\title{
perifèria
}

Número 14, junio 2011

www.periferia.name

\section{"Venderse": de lo sagrado a lo profano a través del mercado y la fusión}

\author{
Irene Gallego Blanco ${ }^{1}$
}

\section{Resumen}

En este artículo se pretende ahondar en la comprensión de los fenómenos que giran en torno a la música denominada World Music. Para ello se ha basado en el trabajo de campo realizado con dos grupos de música de Barcelona, Cumbiambuco y Rumbamazigha. En concreto se analiza cómo a partir de una misma música se construyen distintos discursos sobre la autenticidad y cómo éstos orientan las prácticas musicales de estos grupos, favoreciendo o perjudicando las relaciones interculturales.

Palabras clave: Autenticidad, etnicidad y grupos étnicos, identidad, World Music, música tradicional, mercado y tecnología.

\begin{abstract}
This article aims to analyze the phenomenons which revolve around the music called World Music. This study is based on the field work carried out with two music groups in Barcelona, Cumbiambuco and Rumbamazigha. Specifically, it examines how different discourses about authenticity are constructed within the same type of music and how these guide the musical practices of these groups, favouring or prejudicing the intercultural relationships.
\end{abstract}

Key words: Authenticity, Ethnicity and Ethnical Groups, Identity, World Music, Traditional Music, Market and Technology.

\footnotetext{
${ }^{1}$ Enviar correspondencia a: i.gallegoblanco@gmail.com
} 


\section{perifèria}

Número 14, junio 2011

www.periferia.name

\section{Introducción y cuestiones metodológicas}

La complejidad de un asunto como la World Musicªunque apenas se deje vislumbrar en este artículo, es tal que son infinidad los ámbitos sociales/teóricos que quedan entremezclados. Este ensayo interpretativo se centra en la noción de autenticidad, como cuestión principal a analizar en su relación con la música, y en su repercusión sobre las prácticas e interacciones sociales de estos actores. Los dos grupos de música estudiados (Cumbiambuco y Rumbamazigha) están formados por gitanos rumberos y músicos, colombianos y bereberes, inmigrados aunque residentes en Barcelona. Por tanto se pretende descubrir cómo se articulan estas dos condiciones, ser músico y ser gitano/inmigrante, y entrever hasta qué punto la música como acto comunicativo por derecho, se convierte para estos grupos en un diálogo intercultural de hecho; ver cómo a través de la música los sujetos responden o soslayan tanto el imperativo dialógico, que sentencian las autoridades políticas bajo la rúbrica de multiculturalidad, como la propia necesidad de la diferencia identitaria. La Antropología se presta como disciplina idónea para comprender estas cuestiones sociales. Es su aproximación cualitativa y su capacidad para hacer una etnografía densa lo que le permite desvelar la lógica que subyace en estos comportamientos.

Este artículo es fruto de mi investigación de Máster $^{3}$, un estudio etnográfico más amplio apoyado en cuatro meses de trabajo de campo en el que se trataron cuestiones formales de su práctica musical, como otras de carácter principalmente simbólico. Durante el trabajo de campo se aplicaron los instrumentos "clásicos" de la etnografía y otros facilitados por las nuevas tecnologías. Se realizaron entrevistas semiestructuradas (a los músicos y a otros sujetos relacionados con el mundo de la World Music), observación participante (durante la grabación de un $\mathrm{CD}$, una sesión de fotos y varios conciertos y ensayos) y se revisaron varias producciones mediáticas (revistas de música, myspace, foros de música, etc.).

\footnotetext{
2 Para una mayor comprensión remito al lector a las obras de Bohlman (2002) y Barañano et al. (2003).

3 La World Music: del folklore global a las audiencias locales (2010) durante el Máster Oficial "Investigación Etnográfica, Teoría Antropológica y Relaciones Interculturales" (UAB, 2010).
} 


\section{perifèria \\ Número 14, junio 2011 \\ www.periferia.name}

La experiencia del propio autor como músico facilitó la entrada al campo y orientó los primeros pasos, pero al mismo tiempo se pusieron en cuestión las certezas y los presupuestos del investigador convirtiéndolo "en un sujeto cognoscente que [debía] recorrer el arduo camino del des-conocimiento al re-conocimiento" (Guber 2001:15).

De dicho trabajo se han recogido las ideas referidas al concepto autenticidad a la vez que se han complementado y corregido algunas de ellas con nuevas lecturas teóricas y participación en diversos encuentros científicos. El aumento de eventos y seminarios relacionados con la música y la integración ponen de manifiesto que la música juega un papel relevante en la actualidad y en especial dentro de las políticas sociales. De manera que este trabajo pretende impulsar las investigaciones relacionadas con los hechos musicales dentro de la Antropología, aún minoritarias en España, a la vez que aportar una reflexión crítica sobre vectores ideológicos que dirigen nuestras políticas socioculturales.

Los sujetos investigados son músicos profesionales con una amplia trayectoria musical y amateurs, pero todos ellos comparten por igual la pasión por la música. Cumbiambuco está formado por siete inmigrantes colombianos de edades entre 24 y 47 años. Surgió de forma autónoma constituyéndose como un grupo de música popular-tradicional colombiana. Por otro lado, Rumbamazigha ${ }^{4}$ está integrado por dos bereberes, cuatro gitanos y un leonés, de edades entre 24 y 35 . Surgió a partir de la iniciativa del Taller de Músics ${ }^{5}$ de crear un proyecto sociocultural, y fusionan la música popular bereber con la rumba catalana.

\section{Minorías o mayorías, cuestión de criterio}

Ante la diversidad cultural que constantemente se crea y recrea en Barcelona, los imaginarios actúan para imponer un orden sobre las cosas y las personas, para marcar límites conceptuales, que aunque difusos, garantizan un mínimo de

\footnotetext{
${ }^{4}$ Los siguientes links permiten ver y escuchar a los grupos (http://www.myspace.com/cumbiambuco; www.rumbamazigha.com/). Dada la extensión del artículo al final se adjunta un cuadro resumen donde se pueden ver sus semejanzas y diferencias. Ambos aspectos facilitan la comprensión del artículo pero no son imprescindibles.

${ }^{5}$ Fundación de carácter docente y cultural de Barcelona, sin duda una de las escuelas de música moderna más prestigiosa a nivel europeo. www.tallerdemusics.com
} 


\section{perifèria \\ Número 14, junio 2011 \\ www.periferia.name}

organización a las sociedades urbanas. Las categorías culturales y sus límites articulan la diferencia nosotros-ellos, en una suerte de inclusiones y exclusiones, y sirven para fabricar toda una serie de expectativas normativas y jerárquicas sobre las personas que conforman cada categoría. El problema, entonces, reside no tanto en las distinciones operadas sino en el uso que se da de ellas, por ejemplo, como legitimación de desigualdades y trato diferencial (Delgado 1998).

Estas categorías culturales, entendiendo cultura como forma, estilo de hacer, de actuar (ibídem), son plantillas que diseccionan una totalidad informe y dispersa dando lugar a configuraciones que se superponen, se complementan o solapan en función del criterio cultural seleccionado. $Y$ esto es debido a que los grupos culturales como unidades discretas y delimitadas, con identidad y entidad exclusivas, responden a una ilusión utópica. En Barcelona, las dinámicas polidireccionales y las situaciones imprevistas y fugaces, obligan a los individuos a dotarse de una identidad múltiple y maleable para adaptarse a los continuos choques, encontronazos y negociaciones (Bauman 2005; Delgado 2008). Este desdoblamiento de identidades dificulta cualquier segmentación unitaria y permanente de la ciudad, de tal manera que no podemos hablar de mayorías ni minorías culturales absolutas, sino relativas y temporales (Delgado 1998). Aún así, el término cultura de uso convencional está fuertemente arraigado en las ideas románticas de Gemeinschaft y desencadena toda una serie de asociaciones como nación, lengua, territorio. De esta manera cuando se habla de colombianos, bereberes y gitanos se recurre inconscientemente a una comunidad imaginada (Anderson 2007) que presupone un conjunto de rasgos compartidos, por ejemplo, unas determinadas prácticas o gustos musicales, de los que han nacido en Colombia, Marruecos, Cataluña, etc.

Pero a pesar del carácter ilusorio y fragmentario de la propia identidad, el ser humano necesita dotarse de ella recurriendo a los materiales más disponibles y de mayor saliencia. Al mismo tiempo, necesita identificarse y saberse reconocido por un grupo de referencia. Esta conciencia de pertenencia se activa con mayor o menor fuerza en función de los conflictos, las necesidades y contrarresta la tendencia a la disolución y desagregación que genera la modernidad (Lisón 1994; 


\section{perifèria \\ Número 14, junio 2011 \\ www.periferia.name}

Delgado 2008). Durante el trabajo campo constaté la referencia a esas comunidades imaginadas (gitana, bereber y colombiana) como un resorte de los grupos para reivindicar determinados espacios de participación, arrogarse privilegios musicales y edificar sus identidades musicales. Pero al mismo tiempo, sus adscripciones étnicas quedaban obviadas cuando se referían al mundo musical, una categoría social que, por momentos, cortocircuitaba y sorteaba cualquier nacionalidad, clase o edad. Entonces eran guitarristas, percusionistas o cantantes. Este universo musical barcelonés lo conforman un espectro de agrupaciones que van desde lo amateur a lo profesional y es igualmente diverso y cambiante. En él se pueden encontrar casi todo tipo de músicas o estilos (música clásica, heavy, rock, punk, rumba...).

A pesar de las diferencias que se pueden encontrar en este microcosmos sonoro, la noción de autenticidad aparece como eje transversal a la mayoría de los géneros. Tal y como señala Ochoa (2004:241), bien explícita o implícitamente, esta idea constituye "uno de los valores de mayor importancia adscritos a la música popular" contemporánea en Occidente. A lo largo de los siguientes apartados veremos cómo se articulan algunos de los discursos sobre la autenticidad no exentos de ambages y conflictos.

\section{En torno al concepto de autenticidad}

Es ésta, sin duda, una de las nociones más controvertidas e insidiosas desde la modernidad. Este concepto de uso común se ha ido arraigando en nuestro imaginario constituyéndose como uno de los principales valores que vertebran nuestros juicios morales y pragmáticos. Pero a pesar de la importancia a la hora de configurar nuestras prácticas e ideas, pocas veces se someten a crítica y dilucidación las premisas ideológicas que articulan esta noción y las jerarquías que opera. Si el concepto de autenticidad es deudor de la modernidad, su búsqueda o puesta en práctica no alivia el malestar derivado del individualismo, la prioridad de la razón instrumental, la tecnología y la ciencia (Taylor 1994), bien al contrario es su coartada ideológica. De ahí los malentendidos y las consecuencias nefastas. Los nacionalismos, las nuevas espiritualidades exóticas, los movimientos en torno a la música o el ecologismo ingenuo articulan ideológicamente un discurso en torno a la 


\section{perifèria}

Número 14, junio 2011

www.periferia.name

"verdadera" autenticidad superficialmente diferentes pero con un común denominador: la noción del individuo como valor supremo y lugar de toda vivencia trascendental, una noción que adolece de un sesgo religioso y de puritanismo burgués (Delgado 1999; Bauman 2000).

El término autenticidad no sólo articula un juicio de valor, es decir, no sólo pone en relación dos actitudes, ideas u objetos, sino que se erige como ideal moral, es decir, prescribe un modo de vida, de hacer, de actuar legitimo, mejor o superior (Taylor 1994). Este ideal nos define como individuos, y a la vez, orienta nuestra relación subjetiva con lo que nos rodea (patria, naturaleza, etc.) según una razón instrumental que nos permite ser fieles a nosotros mismos, autorrealizarnos. Esta subjetividad no se establece en función de un deseo o de unas necesidades, sino en función de una norma que dictamina lo que debemos desear o necesitar (ibídem), de tal manera que el concepto de autenticidad mina toda ilusión sobre la universalidad de la libertad e igualdad de todos los seres humanos.

Este giro subjetivo de la modernidad encontró en el arte el correlato secular de experiencia religiosa ${ }^{6}$. Desde el siglo XVIII se gesta una nueva concepción del arte que reemplaza o relega el ideal de imitación por el de creación, imaginación y novedad (Méndez 2009). El arte no se define ya en función de la realidad representada o de su forma de describirla, sino por los sentimientos que suscita. El peso se traslada hacia la obra de arte y su relación con el sujeto privilegiado que sucumbe a su belleza, a su placer. La trascendencia de la experiencia estética se concibe como la vivencia de una esencia intrínseca a la obra capaz de soslayar las presiones para ajustarse a la conformidad exterior. Por eso el arte es el reflejo más puro del yo y de su originalidad, es la sublimación de ese proceso de autodescubrimiento, y la música, dentro de este universo privilegiado, es la forma más espiritual del arte, la negación más radical del mundo social (Bourdieu 1988). Lo sonoro se concibe como el espacio sui generis de la subjetividad, como paradigma de la autenticidad (del yo para la música clásica, del Volksgeist para la

\footnotetext{
${ }^{6}$ Un ejemplo ilustrativo de la relación entre el arte y la religión lo encontramos en la concepción del artista como un alter deus (Méndez 2009:130; Granés 2010:212). Véase también Prats (2004).
} 
perifèria

Número 14, junio 2011

www.periferia.name

música étnica, etc.) de ahí que las nuevas posibilidades de reproducción y grabación brindadas por la tecnología y los medios de comunicación de masas hicieran tambalear todo la artimaña ideológica y clasista de una burguesía consolidada ${ }^{7}$.

Tal y como señala Frith (1986), el desarrollo tecnológico hizo posible el concepto de autenticidad en la música popular. Las músicas modernas han heredado del Romanticismo la idea de que escuchar a alguien es conocerle, es entrar en su alma, y también la concepción folk según la cual la música es una manifestación del grupo en la que los instrumentistas representan y articulan las necesidades, valores y expectativas comunes del grupo (ibídem). La confluencia de ambas concepciones sitúa a la música moderna en una posición incómoda frente a la tecnología y el mercado. Por un lado, porque la tecnología favorece la pérdida de la espontaneidad y de las experiencias genuinas y por el otro, porque obedecer al mercado es faltar a las lealtades del grupo. Ambos factores son los responsables de la alienación de las sociedades urbanas y del malestar de la modernidad. Pero además, para entender la intensidad con la que Occidente construye los discursos de autenticidad en la música frente a otras manifestaciones culturales, artísticas o no, como podrían serlo la pintura o la cocina, es preciso tener en cuenta las características propias de la música y las formas en las que construye espacios de subjetividad.

La música se puede codificar en un lenguaje matemático de alta complejidad racional pero a la vez, su naturaleza abstracta e intangible le hace dependiente de un "cuerpo". Es a través y por el cuerpo ${ }^{8}$, y sus emociones, que el sonido se concreta y adquiere sentido (Ochoa 2004). La música se coloca en una posición ambigua entre la naturaleza y la sociedad, entre lo racional y lo instintivo. La música imita la voz humana o los sonidos de la naturaleza pero es a través de una mediación instrumental que ese sonido, por transubstanciación ritual, se convierte

\footnotetext{
${ }^{7}$ Véase Eco (1972).

${ }^{8}$ A pesar de que los sonidos se perciben a través del sentido auditivo generan una reacción sensorial holística. Es decir, la unidad de la experiencia perceptiva implica que "incluso sonidos musicales aislados tienden a quedar asociados a cualidades generalmente atribuidas a modos no auditivos de percepción" (Meyer 2001:265). Por ejemplo, los sonidos agudos producen una sensación térmica de calor.
} 


\section{perifèria \\ Número 14, junio 2011 \\ www.periferia.name}

en música. Los instrumentos musicales establecen una distancia tecnológica entre la naturaleza -cuerpo- y la sociedad. Además, actualmente la música invade cualquier espacio público o privado, traspasa fronteras, se cuela en los intersticios y fracturas, en situaciones ordinarias y extraordinarias, lo que hace de ella una fuente de poder pero también de peligro. Una música no incrustada está libre para ser instrumentalizada al servicio de intereses económicos, políticos o sociales; moviliza el capital social para la revolución o somete a tortura ${ }^{9}$. Por eso también debe ser controlada, reprimida o censurada.

La ambigüedad y profusión de géneros musicales hoy en día ha supuesto la elaboración de diversos ideales de autenticidad, a veces compartidos y otras aparentemente antagónicos, bajo los que subsume un juicio tanto estético como moral. Pero para que se desarrolle un ideal, es preciso que haya una comunidad que acepte y reconozca los rasgos que conforman ese ideal, es decir, deben compartir un horizonte de significación (Taylor 1994).

Ahora vamos a ver cómo a partir de unas mismas prácticas musicales, las de nuestros sujetos de estudios, se construían y se entrelazaban diferentes ideales de autenticidad: por un lado, el abanderado por la World Music y el diferencialismo cultural, y por otro lado, el de la música étnica de los gitanos catalanes, amazighs y colombianos.

\section{La autenticidad de la World Music}

La World Music se vende como un antídoto para la sociedad urbana y sus experiencias inorgánicas. Permite una vuelta a las primitivas sensaciones más espirituales y verdaderas, una reconciliación con el mundo y la naturaleza, pero al mismo tiempo presupone una distancia insalvable entre ambos universos (Ochoa 2004). Esta música garantiza una experiencia liberadora de la racionalidad y la tecnocracia de las grandes y desalmadas urbes de cemento. Pero este mensaje redentorista, deudor sin duda de la nueva tecnología, proyecta una imagen sesgada

\footnotetext{
9 La instrumentalización de la música puede llevar a extremos insospechados hoy en día. Un ejemplo que pone de manifiesto los usos y abusos de la música, lo encontramos en el seminario internacional organizado en La Virreina Centre de la Imatge con el título "Música y Tortura" (Barcelona, 1718.06.2010).
} 


\section{perifèria}

Número 14, junio 2011

www.periferia.name

y destilada de los otros eternamente primitivos: sin conflictos, ni guerras, ni modernidad. Como señalan algunos autores (Barañano et al. 2003; Martí 1996), esta música pone en relación jerárquica primer y tercer mundo, nosotros-ellos, y sirve de coartada a una nueva forma de racismo o fundamentalismo cultural (Stolcke 1994) ${ }^{10}$ mucho más sutil y ambiguo.

La llegada de "fuertes contingentes" de inmigrantes extra-comunitarios a Europa activó numerosas reacciones a favor y en contra $y$, de igual manera, discursos racistas y antirracistas que tenían en cuenta, más por obligación que por convicción, las diferencias culturales por encima de las diferencias biológicas tradicionalmente asignadas a las razas. Las antiguas categorías jerárquicas que atribuían rasgos de inferioridad moral e intelectual a ciertos rasgos fenotípicos diacríticos, y por tanto heredables e inmutables, fueron parcialmente vaciadas de contenido biológico y rellenadas de nuevo con prejuicios culturales y tergiversaciones científicas (San Román 1996). Apelando al "derecho a la diferencia", los países y sociedades europeas han retomado la idea utópica de nación, patrimonio y valores culturales, como un conjunto propio e inconmensurable, histórica y territorialmente delimitado, para articular toda una retórica de inclusiones y exclusiones. Estas retóricas alimentan el miedo popular a partir de los peligros de desestructuración y alienación derivadas del contacto cultural, y se infiltran en el sentido común y en el habitus. Se han racionalizado dando lugar a dinámicas que tiende a preservar cada grupo de la amenaza de los otros. Un discurso, que en definitiva, presupone la imposibilidad o inviabilidad de cualquier tipo de comunicación y que a través de su "naturalización" desecha cualquier expectativa sobre modelos alternativos, pero que sobretodo, tiende a preservar la hegemonía del sistema de clases (Stolcke 1994). La autenticidad viene garantizada por la pureza cultural y la lealtad de los individuos hacia su nación y su cultura.

\footnotetext{
10 Pese a la antigüedad de los textos (Stolcke 1994; San Román 1996) considero que las ideas fundamentales sobre el racismo siguen siendo válidas, especialmente dada la respuesta de Europa frente a los últimos acontecimientos en el mundo árabe.
} 


\section{perifèria}

Número 14, junio 2011

www.periferia.name

Basándose en este "diferencialismo cultural" la World Music y ciertas políticas socioculturales han importado y diseñado modelos de autenticidad musical no sólo para "nuestra" sociedad, sino para las minorías, los inmigrantes, los del tercer mundo, etc. (Méndez 2009; Ochoa 2004). Y en base a estos modelos, que no tienen en cuenta la relevancia de la música en sus propios países o para los sujetos, sino los intereses de la sociedad capitalista occidental, se les somete a juicio y crítica, se les exhorta a encauzar sus prácticas musicales para su supuesto beneficio.

"...Y les dije [a los gitanos]: 'vosotros lo que sabéis hacer es rumba, no os vayáis por los cerros de Úbeda, reivindicar la rumba y será vuestra fuente de ingresos y de alimentación. Luego que queráis hacer latinjazz, lo hacéis.' Pero para hacer música latina ya están los latinos, ¿sabes?, y los cubanos que te dan mil vueltas. En cambio rumba catalana no hay nadie..."

(Manager de Rumbamazigha)

Las "grandes" oportunidades laborales que se les presentaban a los grupos investigados estaban enmarcadas dentro de programas sociales que acentuaban su condición social, las diferencias culturales y los valores tradicionales (Diversons ${ }^{11}$, Día Internacional del Migrant, etc.). Pero estas diferencias estaban mediadas en muchos casos por viejos estereotipos o por los referentes del mercado musical, lo que en muchos casos dificultaba su participación.

"...La cuestión es que no tengo un manager, y no nos sale [sobre el proyecto Diversons]. Ya lo mandé pero no les interesó porque querían música más tradicional, pero si tú oyes a Totó la Momposina y oyes esto, es más o menos lo mismo. Es más, esto es más limpio que la de Totó, más cercano a algo, la de ella también es folklore pero hay afinaciones raras y eso que ella ha producido en Londres..."

(Pedro, Cumbiambuco)

\footnotetext{
${ }^{11}$ Ver: http://obrasocial.lacaixa.es/ambitos/musica/diversonsconvocatoria2010 es.html
} 


\section{perifèria \\ Número 14, junio 2011 \\ www.periferia.name}

Un programa parecido de la Obra Social La Caixa Catalunya fue, sin embargo, el que impulsó económicamente el proyecto Rumbamazigha. Si partimos de que su música es el producto de una nueva fusión entre música popular amazigh y rumba catalana, el ideal "tradicional" se desvanece. A pesar de ser un ejemplo de integración y diálogo intercultural, hay que preguntarse hasta qué punto el apoyo del Taller de Músics, una entidad catalana, no deja en tela de juicio la viabilidad y transparencia de este tipo de proyectos: un programa social no diseñado como una implementación integral, sino como una fórmula temporal que favorece a grupos individuales y a los propios benefactores, la población catalana. Además, los requisitos explícitos (DNI o NIE de todos los músicos) e implícitos (nivel musical elevado que implica un alto nivel social) excluyen a las minorías más desfavorecidas o en riesgo de exclusión (inmigrantes no regularizados, individuos de bajo poder adquisitivo, etc. $)^{12}$.

En general, la demanda de músicas exóticas, la disponibilidad de subvenciones y posibilidad de conciertos bien -mejor- remunerados, forzaron indirectamente a algunos músicos a abandonar antiguas prácticas musicales (ska, heavy, funky) y a adoptar un estilo tradicional y acorde a su nacionalidad de origen o etnicidad ${ }^{13}$. Pero por otro lado, esta nueva forma de ser músico suponía un recurso disponible y fácil con el que armar una nueva identidad y obtener ingresos económicos. En consecuencia, ellos mismos se arrogaban un privilegio musical y defendían su exclusividad en base a una justificación culturalista y biologista, de tal manera que el proceso de creación respondía más a un instinto de conservación de lo propio que a una elección arbitraria influenciada por un contexto en el que lo exótico con tintes sociales o solidarios vende o se impone ${ }^{14}$.

"...En Colombia hay muchos grupos buenos, de heavy, metaleros o de rock, y que vienen a Europa a dar giras [...] Como colombianos, la música que mejor

\footnotetext{
12 Los paralelismos estructurales y formales entre las ONGs y este tipo de iniciativas socioculturales permiten hacer extensibles algunas reflexiones de Bretón (2005) sobre el funcionamiento y eficacia de las primeras. Véase también Granés (2010).

${ }^{13}$ Véase Méndez (2009).

${ }^{14}$ Véase Granés (2010).
} 


\section{perifèria \\ Número 14, junio 2011 \\ www.periferia.name}

podemos hacer es la nuestra, el folklore, porque lo llevamos en la sangre, [...] toda la música colombiana es lo que mejor podemos hacer y lo que más podemos proyectar por el hecho de ser colombianos..."

(Lucas, Cumbiambuco)

"...Aporte, creo que por sí sola nuestra música muestra lo que somos. Cada vez más la gente conoce de esto [...] aportamos ritmos y temas muy poco, digamos, escuchados o valorados, por así decir, de un pasado cultural innegable para muchos de nosotros porque venimos de ahí..."

(Fran, Cumbiambuco)

\section{La autenticidad étnica}

Las relaciones antagónicas entre sociedades también generan reacción, rechazos y respuestas por parte de los grupos o naciones subordinadas. Colombianos, gitanos y bereberes en Barcelona son considerados grupos culturales en un territorio ajeno, o sin territorio, pero sí con fronteras ${ }^{15}$ más o menos lábiles y permeables que se endurecen y cierran cuanto mayor es la crispación social. Una de las tendencias puestas de manifiesto por varios teóricos (Moreno 2004; Anderson 2007; Lisón 1994) ha sido el refortalecimiento y la activación durante el siglo XX -y XXI- de las etnicidades y los etnonacionalismos, en su versión pacífica o violenta, como respuesta a los nacionalismos de Estado que pretenden eliminar toda pluralidad y disidencia político-cultural.

Tanto gitanos, bereberes o colombianos reconocen y defienden una identidad y especificidad cultural vinculada a una paternidad, valores, lengua y creencias históricamente consolidadas. En estos procesos de autoafirmación y conciencia étnica, la música y otras manifestaciones culturales adquieren un valor específico en función de un horizonte de significación compartido (Martí 1996; Stokes 1994; Prats 2004). En general, la música tradicional colombiana y la rumba catalana, a diferencia de la música bereber, reflejan, en su dimensión axiológica, principalmente la etnicidad. Este valor añadido genera toda una serie de normas y

\footnotetext{
${ }^{15}$ Véase Barth (2004).
} 


\section{perifèria \\ Número 14, junio 2011 \\ www.periferia.name}

códigos de actuación cuya trasgresión se penaliza de una u otra manera ${ }^{16}$. Si la pureza de esta música refleja la lealtad al grupo, cuanto mayor sea la fidelidad y menor el cambio estético, más auténtica será. Los bereberes utilizan, con preferencia sobre la música, otros recursos simbólicos para reivindicar su cultura y reconocerse mutuamente (la lengua, la bandera, etc.).

Este valor dado a la música por los diferentes grupos étnicos nos sitúa ante distintos discursos morales y estéticos sobre la música y su autenticidad en relación con el mercado, la tecnología y la fusión. Según las situaciones, los músicos movilizaban y adaptaban estos discursos, consciente o inconscientemente, para solventar sus propias contradicciones. El mayor conflicto con el que se encontraban era el poder dedicarse profesionalmente a ello, es decir que la música se convirtiera en su principal fuente de ingresos.

"...Estamos muy infravalorados. Si a nosotros mismos no da vergüenza pedirle a alguien: "oye, dame 200 euros por tocar" [...] Tenemos que copiar esto de los gitanos, tendríamos que copiarlo porque es chapó, se venden bien, no se regalan, son putas de lujo. Pero para mí no es indigno ser prostituta, ¿quién no se vende? El obrero vende su cuerpo también, y su salud, su tiempo, su vida. Y lo vende por lo que sea..."

(Jose, payo, Rumbamazigha)

\section{Tocar por amor al arte}

Si partimos de la premisa innegable de que en Barcelona, como en cualquier sociedad capitalista, "ganar dinero es la condición sine qua non de la existencia material y social de cada uno" (Godelier 2008:197) y que los músicos no escapan a este imperativo, ¿por qué se espera de un músico que toque gratis?

En base a la reflexión anterior y la declaración del informante, se puede establecer un paralelismo entre la música y el sexo, y analizar el significado de la metáfora en función de la dicotomía espacio público/profano - espacio privado/sagrado. Estos músicos, como el/la trabajador/a sexual, son personajes públicos aún sin un pleno

\footnotetext{
${ }^{16}$ Véase Cruces (2008).
} 


\section{perifèria}

Número 14, junio 2011

www.periferia.name

reconocimiento, aún sin su totalidad de derechos y deberes, sin cobertura social y a la intemperie. Son seres liminales evitados y deseados por todos ${ }^{17}$, a caballo entre el reino de la reciprocidad y el reino del mercado. Esta metáfora es ilustrativa porque recoge el simbolismo que Occidente ha elaborado respecto al cuerpo. Éste debe ser protegido porque es el continente que guarda lo más sagrado del individuo, su alma, pero también el cuerpo, como fundamento de la sexualidad, debe ser reglamentado y controlado por la sociedad burguesa como garante de la pureza social y racial (Stolcke 2000). Y como dijimos antes, si la música es reflejo del alma y compromete el cuerpo, tocar por dinero es "venderse", prostituirse; es el acto más sacrílego, una profanación. La pérdida de autenticidad por una relación demasiado estrecha con el mercado esconde la lógica de un sistema social y moral más amplio, que queda representado en pequeña escala en el cuerpo (Douglas 2002).

Siguiendo con esta metáfora podemos deducir cómo tenía lugar la praxis musical de estos grupos: por fidelidad y respeto a la comunidad $^{18}$ se veían forzados a disociar ideológica y cualitativamente las esferas ceremonial y la comercial. Los valores eran separables y separados en dos esferas reguladas por lógicas económicas y morales distintas. Esta distinción les permitía sobrellevar las paradojas generadas en su relación con el mercado ${ }^{19}$.

- Pedro: La cuestión era ésta. Otra vez, la señorita aquí presente nos conectó con una persona de una asociación latinoamericana, y que van a montar una fiesta solidaria latina en la parroquia, en la parroquia de la Concepción. Está ahí, en la calle Aragón con Paseo de Gracia. Peros: uno, no hay plata; dos, ella dice que podemos montar una parada para tratar de vender CDS y alguna otra cosa.

\footnotetext{
17 "La inspiración creativa, el genio, representa la excepcionalidad cultural, la individualidad que trasciende, y por tanto trasgrede, las reglas y capacidades culturales que rigen el común de los mortales; los genios son hombres excepcionales" (Prats 2004:23)

18 En este caso el término comunidad no solo se refiere al grupo étnico, también incluye la red de parentesco y amistad, o ciertas asociaciones voluntarias y ONGs.

19 Los músicos de Rumbamazigha, dado que dependían del Taller de Músics, ante esta disyuntiva tocaban con sus otros grupos más informales. El Día contra el Racismo y la Xenofobia organizado por SOS Racisme actuaron gratuitamente con el grupo Asanf.
} 


\section{perifèria \\ Número 14, junio 2011 \\ www.periferia.name}

- Lucas: Mientras haya sonido, y el sonido esté favorable, nosotros tocamos gratis, no hay problema.

- Pedro: El problema es ese, que si empieza a correr la bola de que nosotros vamos gratis.

- Lucas: Pero en el Paseo de Gracia pasan guiris y el otro que compra...

(Conversación entre los miembros Cumbiambuco)

Por un lado, en el sistema externo y global, regido por la economía de mercado y los valores capitalistas, la "multiculturalidad" estaba definida por relaciones antagónicas y la música era expresamente pública, secular y lúdica. Por otro lado, en el grupo interno y local, regido por la lógica de la reciprocidad y redistribución, las ceremonias eran de carácter sagrado y/o pertenecían al ámbito privado. Como se puede apreciar, la música "está incrustada y enredada en instituciones económicas y no económicas" (Polanyi 2008:35).

Los músicos se ven obligados a un continuo devaneo entre sus necesidades materiales y sus obligaciones morales. Como pude comprobar durante el trabajo de campo, las condiciones laborales, el significado y la forma de la música, y su carácter sagrado o profano venían determinados por la situacionalidad. De esta forma, las canciones tradicionales o rituales eran, muchas veces, adaptadas estructural y estéticamente a los patrones de la música popular contemporánea y a su demanda.

"...A veces aquí, cuando vamos a un sitio donde hay gente, suben todos al escenario. $Y$ no puede ser, porque nosotros tenemos unas cosas organizadas y temas, y a lo mejor lo hacemos diferentes de lo que hay allá, hacemos un poco de todo, pero diferente, para que la gente no sepa que estamos tocando, pero que realmente tienen relación. Porque la gente está acostumbrada a ir a una boda y participar. Hay un instrumento, la pandereta y va turnando todo el rato..."

(Abian, bereber, Ruambamazigha) 


\section{perifèria}

Número 14, junio 2011

www.periferia.name

La lógica cartesiana, deudora de la concepción judeocristiana, vertebra el imaginario occidental y opone radicalmente lo sagrado a lo profano. Occidente a través de esta dicotomía ha seccionado la experiencia social y ha llenado de contenido material y normativo cada una de estas categorías. Lo sagrado, y la religión como paradigma, es aquello que está protegido, idealmente, de los principios de mercado. Pero hay que tener en cuenta que nuestra concepción sobre lo sagrado no es universal, de manera que lo que para nosotros supone una infracción o conflicto mora,l puede no serlo para otras culturas.

"...Yo creo que los sonidos y la música están en el aire, y si no lo hago yo, lo hace otro. [...] y si tú te sientes bien con ello es suficiente [...] por ejemplo, la danza de la pubertad, bueno, si hubiera alguna cosa que sirviera, personalmente yo creo, que soy de allí, que no importaría tanto rescatar algo de allí para hacerlo comercial, al fin y al cabo es belleza, y bueno, si la gente lo quisiera ya está [...] Si la danza del Txopoteke fuera pegadiza pues igual la gente lo consumiría pero realmente creo que si se ha salvado la parte sagrada ésta del ritual es porque no son pegadizas..."

(Pedro, Cumbiambuco)

Actualmente, las músicas tradicionales que pertenecían al acervo popular han sucumbido a las fuerzas económicas regidas por los principio de mercado. Su revalorización (¿moda?) y venta a través del mercado regional e internacional, bajo el lema "todo es vendible", retoma un viejo debate en torno a la desacralización (profanación), la apropiación y los derechos de autoría (Méndez 2009). Cada grupo social y cada individuo se provee de sus propias lógicas, retrospectivas y prospectivas, que legitiman y dan sentido a sus actos (Bourdieu 1989). La racionalización de las contradicciones permite obviar las distancias entre principios y prácticas, actos y palabras, y aprehender la experiencia como un todo coherente y unificado.

"...Lo que hago yo es todo lo contrario, es música para bailar, absolutamente profana y absolutamente vulgar. [...] Pero bueno, es distinto, pero sí que he tocado mucha música judía de bodas, pero no creo que se lo tomen a mal, no 


\section{perifèria \\ Número 14, junio 2011 \\ www.periferia.name}

creo. Me gustaría saber que opinan y que entendieran que lo hago con el máximo respeto. [...] Yo trato de documentarme siempre, un poco sobre lo que estoy tocando, de lo que estoy hablando [...] Me pasó con este grupo [Arabeske] por ejemplo, haciendo un bolo [...] es un estilo que no domino, y me daba mucha vergüenza [...] Le puede decepcionar pero no molestar. A mí no me molesta escuchar música mediocre, me puede decepcionar pero no me molesta. ¿Cómo no lo vas a admirar, alguien que viene, recorre kilómetros y kilómetros para conocer tu música y tu cultura y tocarlo?..."

(Jose, payo, Rumbamazigha)

El análisis del papel del mercado musical no debe dejar pasar por alto los aspectos positivos sobre las comunidades.

"...Pero ahora también hay grupos comerciales, desde la cinta, el CD, entonces empieza a ser comercial, hay productoras. De un lado está bien, de otro está mal comercializar, pero da vida y continuidad a una cosa..."

(Abian, bereber, Rumbamazigha)

A raíz de la popularidad de la World Music algunas minorías étnicas han encontrado en la música una vía de lucha política y una fuente de ingresos económicos. La música popular provee del modo a través del cual los propios individuos y la comunidad afectada ganan prestigio y estatus social. El caso del flamenco es paradigmático de la mediación del mercado entre lo regional y lo internacional, y cómo ha sugerido Steingress (2004:12), su evolución "siempre se ha visto sujeta a una permanente adaptación artística al entorno económico capitalista y a la cultura de masas".

Tampoco hay que olvidar que cobrar por tocar tiene una implicación no solamente económica, sino también simbólica. Fijar un caché es valorarse y esperar que los otros te valoren, es una forma de potenciar el reconocimiento artístico y la profesionalización. A pesar de que el dinero actúa como indicador de calidad en la música, los principios de mercado operan generando modas y famosos, y a diferencia de lo que ocurre en otros ámbitos laborales, no tanto la calidad como la fama es la condición para la popularidad y oportunidades laborales. La industria 


\section{perifèria \\ Número 14, junio 2011 \\ www.periferia.name}

cultural acerca paradójicamente la música popular al arte: si la música se paga, y caro, es porque es un arte. Si se habla de arte no se habla de dinero, el arte no permite el regateo ni la oferta.

"...Si, he tocado y no he cobrado. [...] Y con la entrada depende, si son 3 ó 4 euros la gente paga, pero si son 15 ya no vienen si no te conocen. La gente que paga va a ver lo que haces. Pero para cobrar entrada tienes que tener un nombre si no, no te va a oír nadie..."

(Dani, gitano, Rumbamazigha)

Aunque Cumbiambuco y Rumbamazigha no participaban de la World Music de las grandes empresas discográficas, la demanda música exótica en Barcelona y los programas de "multiculturalidad" les proporcionaban unos espacios donde visibilizar y materializar su especificidad étnica e idiosincrasia musical como banda. La puesta en escena permitía hacer públicas sus aspiraciones y reivindicaciones políticas y artísticas, a la vez que les posibilitaba -inestable y precariamente- una fuente de ingresos.

En definitiva, se puede decir que estos grupos articulaban las dos lógicas o cosmovisiones (local y global) según la regla de los dones-contradones agonísticos, es decir, en base a "una regla de derecho que explica que los bienes preciosos que circulan en los dones tengan un uso alienado $\mathrm{y}$ al mismo tiempo sigan siendo propiedad inalienable del donante original" (Godelier 2000:205). Este principio se aplica a los objetos preciosos (música) y no a los objetos sagrados (ceremonia ritual). A pesar de que las industrias discográficas occidentales ven estos productos como una mercancía alienable, capaz de entrar en los flujos financieros de un mercado en boga, los grupos en sus actuaciones no están haciendo un intercambio de música por la música, sino que ofrecen un regalo inalienable que es lo que, de una manera como tantas otras, consiste en ser amazigh, gitano o colombiano. 
perifèria

Número 14, junio 2011

www.periferia.name

\section{Tecnología naturalizada}

La gran difusión y aceptación de la World Music y éxito de los festivales de Músicas del Mundo $^{20}$ y de folklore han impulsado a muchos músicos contemporáneos a retomar el carácter nómada de los juglares, con la particularidad de que ahora traspasan las fronteras étnicas y nacionales. Se puede decir que los músicos actuales, especialmente los del sector informal ${ }^{21}$, son músicos mucho más globales. Con esta idea quiero matizar dos aspectos principales que les diferencian de los músicos tradicionales: por un lado la desterritorialización (física y virtual), y por otro lado, la desencialización. Con esto segundo me refiero a que hoy en día un músico interpreta muchos estilos, algunos propios de su cultura y otros asociados tradicionalmente a otra cultura (transculturación artística ${ }^{22}$ ) en una tendencia general hacia el eclecticismo musical.

El abaratamiento de los equipos de grabación y producción musical les permite a estos músicos hacer sus propias creaciones y mezclas, y difundirlas a través de Internet. $Y$ al mismo tiempo, las redes de descarga de archivos musicales 0 streaming se han convertido en un medio de aprendizaje informal e influencia, en un momento en que la oferta y demanda local se ve desbordada de productos de todas partes. Como pude observar en el trabajo de campo, algunos músicos colombianos habían aprendido en Barcelona a tocar los instrumentos o el repertorio tradicional de su país a través de Internet. Pero también la red les permitía traspasar o solventar las limitaciones de la propia cultura musical y enfrentarse a los convencionalismos y prejuicios (los gitanos estaban aprendiendo jazz y funky).

"...He tocado con mi padre y con el padre de Pelu. iUy! , es muy complicado, no puedes tocar como quieras, yo en Rumbamazigha hago lo que quiero. Con

\footnotetext{
20 Mar de Músicas, WOMAD, Etnosur, Pirineos Sur son algunos de los festivales de Músicas del Mundo más importantes a nivel estatal.

${ }^{21}$ La praxis de ambos grupos tenía lugar dentro del sector informal de la economía, tal y como lo define Ubaldo Martínez Veiga (2008) (cit. en Gallego 2010). Una de las características de este sector es su flexibilidad a la hora de adaptarse a los cambios y a las demandas como una estrategia de supervivencia. De ahí que muchos músicos tengan que tocar en varios grupos a la vez o realizar diversos oficios simultáneamente (diversificación).

22 Véase Kartomi (2008).
} 


\section{perifèria \\ Número 14, junio 2011 \\ www.periferia.name}

ellos no. Es otra manera de ver la música, son más cerrados. A nosotros nos gusta investigar. -A ver este acorde raro- "aquello esta desafiado, nen", te dicen. Es otra mente..."

(Dani, gitano, Rumbamazigha)

Aunque esta nueva forma de autoaprendizaje permite a los músicos desafiar el establishment cultural y social, hay que decir que para aprovechar eficiente y subversivamente sus recursos, es imprescindible partir de una base musical previamente adquirida.

Como vamos viendo, tanto Cumbiambuco como Rumbamazigha eran grupos contemporáneos de música popular - aunque de corte etnicitario- que dependían de ciertos adelantos tecnológicos como el micrófono, los altavoces, los equipos de grabación, etc. Estos elementos, que obviamente no aparecen en las prácticas tradicionales rigurosas, son hoy en día tan familiares, que su presencia apenas se tiene en cuenta o se cuestiona. La "invisibilidad" de la tecnología actual y su "naturalización" (Adell 2008) traslada la crítica sobre la autenticidad de la grabación a su puesta en escena, de lo virtual a lo visual. De ahí que la relación de estos grupos con la tecnología se ponía de manifiesto principalmente a través de los instrumentos.

"...Con ellos hicimos una presentación el año pasado. La música que hacen me parece un poco más de fusión, manejan los temas tradicionales pero un poco más de fusión. Típicamente no manejan todos los instrumentos como para un grupo de folklor neto, pero sí, tuvimos una buena experiencia con ellos..."

(Bailarín de folklore colombiano)

Las músicas tradicionales suelen llevar asociados determinados instrumentos autóctonos a cada género y sólo un profundo conocimiento de la cultura musical permite reconocerlos o enjuiciarlos. Actualmente, dada la gran disponibilidad de instrumentos, a la hora de buscar sonidos exóticos se tiene más en cuenta la cualidad tímbrica que el origen del instrumento. Esto responde a que el timbre es un "signo de personalidad individual" muy valorado en la música popular desde el siglo XX (Frith 2008:429), pero también debido a las tergiversaciones provocadas 


\section{perifèria \\ Número 14, junio 2011 \\ www.periferia.name}

por la World Music ${ }^{23}$.

"...Le da el toque, en teoría le da el toque. Tienen otro instrumento pero se desafina, una cosa muy rara, se desafina...y al final tiró por el banjo..."

(Manager de Rumbamazigha)

La combinación de instrumentos, tanto modernos como "extraños", da lugar a una fusión de ritmos, timbres y armonías que permiten deslizarse de un género a otro, a través de la búsqueda e innovación de nuevas experiencias sonoras:

"...lo que hacemos nosotros es...fusionamos sin pasarse. En Rumbamazigha está la base de la rumba, lo que es fundamental: guitarra, ventilador y palmas, y la voz, ¿vale?, y los músicos amazigh ¿qué hacen? darbukas, djembes y banjo, o sea, que tampoco la prostituimos por llamarlo de alguna forma. No ponemos ni guitarras eléctricas ni batería, tampoco nos...está la esencia de la rumba..."

(Pelu, gitano, Rumbamazigha)

En la música de corte tradicional los instrumentos juegan un papel legitimador fundamental pero, sin embargo, la música es un proceso de formas nunca acabadas en el que es común el préstamo y la difusión entre culturas musicales. La dialéctica entre la autenticidad y fusión activaba toda una serie de justificaciones con la que lo músicos pretendían dotar de coherencia al propio proceso de creación musical.

\section{Fusión o trasgresión}

La actual tendencia de los grupos a fusionarse se ha debido en gran parte a la tecnología y al mercado. La disponibilidad de músicas de casi todos los rincones del planeta, a través de Internet, tiendas de discos o bibliotecas, ha estimulado la curiosidad y creatividad de los músicos, generando al mismo tiempo nuevas audiencias. Pero, sin embargo, sus transgresiones estéticas podían ser descalificadas o no reconocidas por sus respectivas comunidades imaginadas.

\footnotetext{
${ }^{23}$ Como ejemplo se puede citar el caso de la Sweet Lullaby, una nana de los Baegu procedente de las islas Salomón, editada dentro de las Fuentes Musicales de la UNESCO, que reeditó en posteriores CDs como una canción proveniente del África Central (CD:Deep Forest y CD: Visible World) (Barañano et al. 2003).
} 


\section{perifèria \\ Número 14, junio 2011 \\ www.periferia.name}

Empezando por Cumbiambuco podemos decir que a pesar de que fusionaban el estilo y los instrumentos tradicionales con otros más modernos, en una clara tendencia hacia el pop comercial, sus compatriotas reconocían su música como un producto colombiano y se sentían identificados con lo que hacían. El pop puede categorizarse como una música étnica (¿europea?), difundida y asimilada por otras culturas, pero convencionalmente se le ha desprovisto de este valor etnicitista y se la considera un producto neutro por lo que no interfería en la autenticidad de Cumbiambuco, entendida en términos de fidelidad a la cultura nacional. Además, esta tendencia hacia el pop colombiano venía influenciada por el éxito de grupos cómo Carlos Vive en Colombia.

En lo referido a Rumbamazigha tenemos que partir del hecho que esta música fusionaba dos tradiciones culturales distintas y con un fuerte sentimiento étnico. El posible reconocimiento podía venir de lado de la comunidad bereber en Barcelona, de los rumberos o de ambos. Tal y como dijimos anteriormente, la música bereber no está estrechamente vinculada a la etnicidad, por lo que su fusión en términos estéticos o étnicos no generaba ningún conflicto respecto a la autenticidad, también entendida como fidelidad al grupo. Los amazighs que acudían a los conciertos participaban activamente en la puesta en escena, se sentían identificados y Rumbamazigha obtenía el reconocimiento y beneplácito de su comunidad. Por parte de los rumberos gitanos, se puede decir que el reconocimiento era parcial y conflictivo.

Para entender esta postura ortodoxa hay que tener en cuenta que los gitanos rumberos a través de su música reivindican, en un principio, su catalanidad y contrarrestan la actual tendencia política que les categoriza cómo minoría étnica equiparándolos a los inmigrantes $y$, en especial, a los gitanos rumanos. La comunidad gitana en Barcelona, lejos de presentar una cohesión y unicidad sin conflictos, está segmentada jerárquicamente en gitanos catalanes, gitanos "peludos" (no catalanes) y romá (gitanos del Este de Europa) lo que da lugar a un juego de distinciones identitarias y hostilidades (Marfá 2007a). A pesar del estigma que pesa sobre los gitanos en general, los gitanos catalanes detentan un estatus social y económico más elevado y participan activamente en las formas de vida 


\section{perifèria \\ Número 14, junio 2011 \\ www.periferia.name}

hegemónicas (Marfà 2007b). En este contexto de conflicto y antagonismo la música asume un papel fundamental frente a otros rasgos culturales asociados a la catalanidad, como la lengua, o un asentamiento históricamente consolidado, que sólo es comprensible a la luz de su vinculación con el cuerpo. El cuerpo es el soporte y vehículo de la música pero a la vez determina la condición social, racial y hasta ciudadana. Tal y como apunta Stolcke (1994:249), "la nacionalidad no es tan distinta de la forma en la que funcionaban los principios de parentesco".

Los gitanos catalanes reivindican el reconocimiento oficial de la rumba catalana como manifestación tradicional y $\operatorname{popular}^{24}$ de la identidad catalana, en un momento en que su estatus socioeconómico se ve amenazado por la llegada de inmigrantes de Europa del Este ${ }^{25}$. Esta demanda se articula estratégicamente con los intereses de la sociedad mayor en un momento en el que tienen lugar, por parte de las instituciones políticas catalanas, numerosas iniciativas de fortalecimiento y recuperación cultural.

En este juego de intereses en torno a la rumba catalana se han generado acalorados debates en torno a la autenticidad de las numerosas propuestas que se adscriben a este género musical. Por ello, la autenticidad de Rumbamazigha, aunque se debatía en términos estéticos, realmente implicaba un conflicto social más profundo. El resto de los gitanos afirmaba que no se trataba de rumba catalana stricto sensu, evidenciando el esfuerzo implícito por desmarcarse de los amazighs y de los inmigrantes en general.

Los juicios de autenticidad combinan tanto reglas relativas a la contaminación como a la moral. Como ya vimos, las reglas de la moral se aplicaban a la relación de la música-mercado y eran mucho más abstractas y ambiguas (Douglas 2002). Su aplicación en cada contexto particular podía variar, y principalmente se entendía como una cuestión de grados de moralidad o inmoralidad. Respondían a un

\footnotetext{
${ }^{24}$ Véase Álvarez et al. (1995).

${ }^{25}$ En diciembre de 2008 tuvo lugar en Barcelona el Primer Simpòsium Nacional de la Rumba Catalana en el Centre Artesà Tradicionarius (CAT) del barrio de Gracia.

http://www.sibetrans.com/obrir_arxiu.php?arxiu=/etnoboletin/ETNO_Revista_Musica_Cultura_01_2009. pdf
} 


\section{perifèria}

Número 14, junio 2011

www.periferia.name

equilibrio entre derechos y deberes, cuya posible infracción recaía sobre los propios individuos. Sin embargo, las reglas de contaminación eran inequívocas, categóricas, y respondían a una lógica binaria contaminado/no contaminado que equivalía a rumba/no rumba. El castigo de los problemas de contaminación era impersonal, no predefinido o colectivo. Es decir, por detrás de cualquier juicio estético sobre la rumba catalana, lo que estaba en juego era el estatus socioeconómico de la comunidad gitana catalana, el poder de la clase.

Resumiendo, se puede decir que desde el punto de vista estético la audiencia de Barcelona reconocía a Cumbiambuco como un grupo de pop-folk y a Rumbamazigha cómo un grupo de fusión (o mestizaje). A pesar de que los límites de las categorías son siempre confusos, estas etiquetas les garantizaban o les privaban de determinados espacios de participación.

\section{Conclusiones}

A lo largo de este artículo se ha visto cómo a partir de una mismo hecho musical se pueden elaborar distintos discursos sobre la autenticidad, en ocasiones contradictorios. El concepto de autenticidad sirve para establecer fronteras entre lo puro y lo contaminado, lo legítimo e ilegítimo con serias repercusiones a la hora de diseñar espacios y políticas de participación. La autenticidad adjetiva unos determinados comportamientos culturales, al tiempo que los naturaliza. Es decir, prescribe determinados gustos y prácticas musicales a grupos sociales entendiéndolos como un hecho dado e inmutable. Una arqueología de este concepto pone de manifiesto su relativa juventud y los cambios habidos en su génesis, trastocando la supuesta inevitabilidad de los hechos que describe. La práctica común y cotidiana de esta noción, su eficacia a la hora de manejar intereses y diseñar estrategias de control social, muestran que la autenticidad existe en nuestros imaginarios, pero su funcionamiento real dista mucho de aquello que preconiza.

Partiendo de este hecho, de que la autenticidad existe como operador semántico y práctico, su análisis obliga primero a entenderlo como un concepto relacional en constante negociación y actualización, y segundo, al estudio de los principales 


\section{perifèria}

Número 14, junio 2011

www.periferia.name

rasgos que lo componen, de su peso relativo y cambiante con el tiempo. En este trabajo nos hemos adentrado en el estudio de la tecnología y el mercado, pero otros muchos, en especial el papel de la "fama" y el lugar de escenificación (calle, plaza, teatro, etc.) resultan igualmente relevantes e imprescindibles.

Tabla1. Resumen comparativo de los casos de estudio

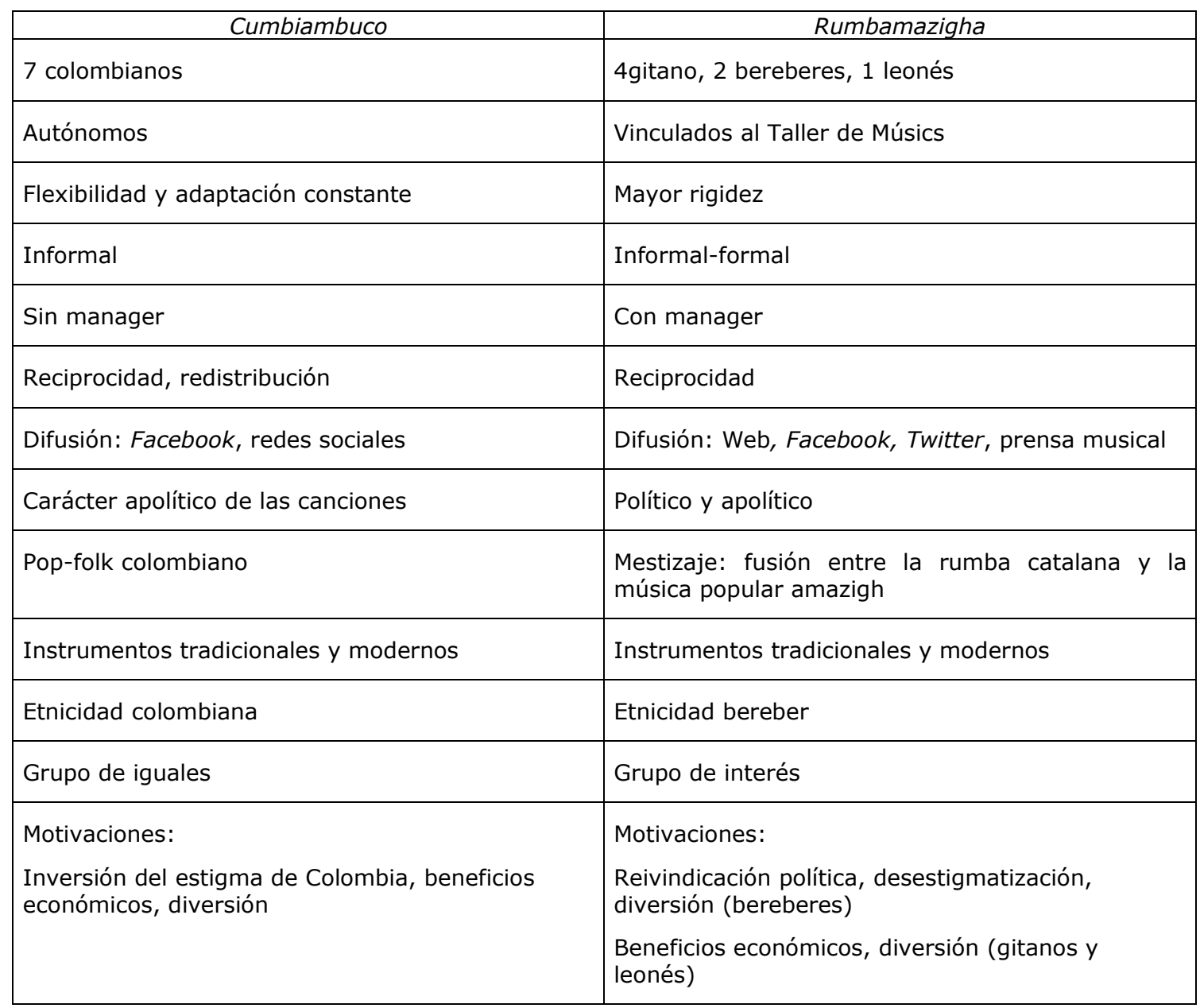

Fuente: Gallego 2010 
perifèria

Número 14, junio 2011

www.periferia.name

\section{Bibliografía}

Adell, J. (2008)."Músicas portátiles: tecnología y evolución del consumo musical" en Miguel de Aguilera et al. (eds). Comunicación y música II. Barcelona: UOC, pp. 2775.

Álvarez, A.; Iglesias, D.; Sánchez, J. (1995). Sabor de rumba. Lleida: Pagés.

Anderson, B. (2007) [1983]. Comunidades Imaginadas. México D.F.: Fondo de Cultura Económica.

Barañano, A., Martí, J., Cruces, F. y De Carvalho, J.J. (2003). "World Music, ¿El folklore de la globalización?". Trans Revista Transcultural de Música, nº 7.

Barth, F. (2004) [1976]. "Los grupos étnicos y sus fronteras. Introducción" en Nuria Fernández (comp.). Lecturas de Etnología. Madrid: UNED ediciones, pp.97121.

Bauman, Z. (2005). Identidad. Madrid: Losada.

(2009) [2000]. Modernidad Líquida. Buenos Aires: Fondo de Cultura Económica.

Bohlman, P. V. (2002). World Music: A Very Short Introduction. New York: Oxford University Press.

Bourdieu, P. (1988) [1979]. La distinción. Madrid: Taurus. (1989). "La ilusión biográfica". Historia y Fuente Oral, n. 2, pp. 35-39.

Breton, V. (2008). "Las Organizaciones No Gubernamentales y la privatización del desarrollo rural en América Latina", en Paz Moreno Feliú (comp.). Entre las gracias y el molino satánico. Madrid: UNED ediciones, pp. 463-485.

Cruces, C (2008). "El aplauso difícil. Sobre la "autenticidad", el "nuevo flamenco" y la negación del padre jondo" en Miguel de Aguilera et al. (eds). Comunicación y música II, Barcelona: UOC, pp. 167-211.

Delgado, M (1998). "Dinámicas identitarias y espacios públicos". Revista Afers Internacionals 43-44, Barcelona: Fundació CIDOB, pp. 17-33. 


\section{perifèria}

Número 14, junio 2011

www.periferia.name

(2008) [1999]. El animal público. Barcelona: Anagrama.

Douglas, M (2007) [1966]. Pureza y peligro. Buenos Aires: Nueva Visión.

Eco, U. (1990) [1968]. Apocalípticos e integrados. Barcelona: Lumen.

Frith, S. (1986). "El arte frente a la tecnología: el extraño caso de la música popular". Papers, n029, pp.178-196.

(2008) [1987]. "Hacia una estética de la música popular" en Francisco Cruces (ed.). Las culturas musicales. Madrid: Trotta, pp. 413-437.

Gallego, I. (2010). La World Music en Barcelona: del folklore global a las audiencias locales. Barcelona: UAB. (Inédito)

Godelier, M. (2008) [2000]. "Acerca de las cosas que se dan, de las cosas que se venden y de las que no hay que vender ni dar, sino que hay que guardar: una reevaluación crítica de El ensayo del Don de Marcel Mauss" en Paz Moreno Feliú (comp.). Entre las gracias y el molino satánico. Madrid: UNED ediciones, pp. 195211.

Granés, C. (2010). "Revoluciones modernas, culpas posmodernas" en Carmelo Lisón (ed.). Antropología: horizontes estéticos. Barcelona: Anthropos, pp. 211-246.

Guber, R. (2001). La etnografía, método, campo y reflexividad. Bogotá: Norma,

Kartomi, M. (2008) [1981]. "Procesos y resultados del contacto entre culturas musicales: una discusión de terminología y conceptos" en Francisco Cruces et al. (eds.). Las Cultural Musicales. Madrid: Trotta, pp. 357-383.

Lisón C. (1994). "Etnicidad y violencia" en José A. Fernández de Rota y Monter (ed.). Etnicidad y violencia. A Coruña: Universidade da Coruña, pp. 9-20.

Marfá, M. (2007a). "Estudio sobre prácticas religiosas pentecostales y construcción de identidades entre los gitanos catalanes de Barcelona" en Congreso Internacional "La mirada antropológica entre lo global y lo multicultural", Mérida: Asamblea de Extremadura-Consejo de derecho consuetudinario y antropología.

(2007b). "De lejos y de cerca. Diferenciaciones y negociaciones identitarias entre gitanos catalanes y romá procedentes de Rumanía" en Training Seminar 


\section{perifèria \\ Número 14, junio 2011 \\ www.periferia.name}

2007: "La política de lo diverso: ¿Producción, reconocimiento o apropiación de lo cultural?", Barcelona: Fundació CIDOB.

Martí, J (1996). "Musica y Etnicidad: una introducción a la problemática" en Trans Revista Transcultural de Música, n².

Martinez Veiga, U (2008) [1989]. "El otro desempleado: el sector informal" en Paz Moreno Feliú (comp.). Entre las gracias y el molino satánico. Madrid: UNED ediciones, pp. 411-463.

Méndez, L. (2009). Antropología del campo artístico. Madrid: Síntesis.

Meyer, M. (2001) [1956]. Emoción y significado en la música, Madrid: Alianza.

Moreno, I. (2004) [1994]. "¿Violencia étnica o violencia de Estado?: nacionalismos estatalistas, etnonacionalismos y minorías étnicas" en Aurora Marquina (comp.). El ayer y el hoy: lecturas de Antropología política (I). Madrid: UNED ediciones, pp. 411-435.

Ochoa, A. M. (2004) [1998]. "El desplazamiento de los espacios de la autenticidad: una mirada desde la Música" en Aurora Marquina (comp.). El ayer y el hoy: lecturas de Antropología política (II). Madrid: UNED ediciones, pp. 233-253.

Polanyi, K. (2008) [1957]. "El sistema económico como proceso institucionalizado" en Paz Moreno Feliú (comp.). Entre las gracias y el molino satánico. Madrid: UNED ediciones, pp. 233-261.

Prats, L. (2004). Antropología y patrimonio. Barcelona: Ariel.

San Román, T. (1996). Los muros de la separación, Bellaterra: Tecnos.

Steingress, G. (2004). "La hibridación transcultural como clave de la formación del Nuevo Flamenco". Trans Revista Transcultural de Música, n8.

Stolcke, V. (2000). "¿Es el sexo para el género lo que la raza para la etnicidad...y la naturaleza para la sociedad? Política y Cultura, no. 014, México D.F, pp. 25-60.

(1994). "Europa: nuevas fronteras, nuevas retóricas de exclusión" en Dolores Juliano et al. Extranjeros en el Paraíso. Barcelona: VIRUS, pp. 235-267. 


\section{perifèria}

Número 14, junio 2011

www.periferia.name

Stokes, M (1994). "Introduction: Ethnicity, Identity and Music" en Martin Stokes (ed.). Introduction: Ethnicity, Identity and Music. Oxford: Berg, pp.1-29.

Taylor, C. (1994). La ética de la autenticidad. Barcelona: Paidós. 